\section{O sentido da representação, quando se era apenas oposição}

Paulo Roberto Figueira LEAL. O PT e o dilema da representação política: os deputados federais são representantes de quem? Rio de Janeiro, Editora da FGV, 2005, 126 páginas.

\section{Cláudio Gonçalves Couto}

Chega ao público num momento dramático da vida petista o livro de Paulo Leal sobre o Partido dos Trabalhadores. Após as denúncias do "collorido" deputado Roberto Jefferson (PTB), de que um esquema de remuneração de parlamentares aliados e de "caixas-dois" de campanhas eleitorais seria mantido pelo PT e seu governo, nunca mais a agremiação será a mesma. Se é que ainda será algo, pois restam dúvidas até mesmo quanto às possibilidades de sua sobrevivência. Neste cenário, a conjuntura ofusca o lançamento de uma obra que visa a discutir o significado da representação legislativa para os parlamentares do partido. Todavia, como uma obra acadêmica que é, merece ser avaliada - para além de sua importância conjuntural - como uma contribuição para que se compreenda o fenômeno da representação política em geral e de sua significação para o partido hegemônico da esquerda brasileira nos últimos vinte anos do século passado.

O livro divide-se em quatro capítulos. No primeiro, o autor discute diversas concepções acerca das disputas eleitorais contemporâneas, marcadas pela personalização das campanhas eleitorais, pela centralidade da mídia e pelo ganho de relevo das técnicas de propaganda e marketing eleitoral. Elabora essa discussão à luz da teoria clássica da representação política, opondo as noções de mandato imperativo e livre, procurando compreender de que forma o PT lida com essa miríade de problemas, considerando o contexto institucional brasileiro e, dentro dele, a peculiaridade petista - por se tratar de uma agremiação mais marcadamente ideológica do que suas congêneres nacionais.

Ainda nesse primeiro capítulo o autor aponta os pressupostos de sua pesquisa. Indica que busca- rá aferir (1) em que medida para o PT está claro que o mandato parlamentar é subordinado às injunções partidárias; (2) qual a lealdade principal dos parlamentares no exercício de seu mandato; (3) como se compõem os gabinetes dos deputados, "quem trabalha neles, como funcionam, a quem atendem", assim como se define a agenda do parlamentar; e (4) como os parlamentares conciliam sua busca individual maximizadora de votos com as exigências petistas de representação delegada. Daí formula a hipótese central de seu trabalho:

[...] embora a atuação legislativa do deputado petista seja fortemente influenciada pelas decisões partidárias coletivas, o deputado modal na bancada do PT - sobretudo aquele com estreita dependência de bases eleitorais concentradas em grupos sociais organizados como movimentos sindicais ou sociais - tende a deslocar grande parte de seu esforço para a organização de seu gabinete. [...] os deputados tenderiam a concentrar tempo, esforço e recursos legislativos na transformação da estrutura de seu gabinete em máquina eleitoral (p. 33).

No segundo capítulo, Paulo Leal discute de forma panorâmica a literatura existente sobre o PT, observando que esta se dividiu em diferentes ciclos e entre diversas disciplinas: os primeiros estudos focaram-se na gênese do partido e na diferenciação do PT com relação às demais agremiações brasileiras; o segundo ciclo privilegiou a experiência petista da chegada ao poder; o terceiro conjunto de trabalhos focou-se nas transformações do partido e suas crises identitárias; e um último conjunto tratou da degeneração do partido, criticando-o, ora à direita, ora à esquerda. Com base em seu levantamento bibliográfico, o autor nota uma lacuna, que buscará preencher, qual seja, estudos que se debrucem sobre as estratégias dos parlamentares petistas, premidos tanto pela maximização de suas possibilidades eleitorais como pela institucionalidade partidária.

Daí, no terceiro capítulo, o autor discutir o arcabouço institucional petista e a maneira como o partido lida com a questão da representação. Retoma a dicotomia entre mandatos delegados e livres, transpondo-a para a oposição entre a representação como espelho e a representação como filtro. Identifica preocupações que marcaram a gênese da concepção petista de representação: a ne- 
cessidade de um partido dos trabalhadores em particular, a preponderância das instâncias partidárias sobre os mandatos eletivos e a contemplação da representação das minorias no interior do partido, mediante a adoção da proporcionalidade.

No quarto capítulo, Leal procura identificar os "princípios e práticas hegemônicas na bancada petista". Para tanto, aplicou um questionário aos parlamentares e, com base na tabulação das respostas, identificou as visões predominantes sobre o mandato parlamentar. Folgada maioria dos legisladores petistas (61\%) considerou que "o mandato é eminentemente partidário, mesmo que em desacordo com os desejos da base". Este montante superou largamente as opiniões segundo as quais o mandato parlamentar deveria ser exercido como uma delegação, seja dos eleitores, seja dos movimentos sociais, ou ainda, como um exercício de consciência - nenhuma delas atingiu 15\%. A esmagadora maioria dos parlamentares também considerou adequado fechamento de questão (98\%) e não desejava mais liberdade para decidir (83\%). Isto mostra o quanto os representantes petistas valorizavam o direcionamento partidário de sua atuação - ao menos enquanto o PT estava na oposição, já que a coesão partidária caiu drasticamente ao longo do governo Lula (a enquête foi aplicada no final da legislatura que antecedeu a experiência do partido no governo federal). Outras respostas apontam em direção similar.

Essas respostas contrastam, todavia, com as referentes à composição do gabinete parlamentar. Questionados quanto ao critério prioritário de contratação dos assessores, 42,5\% afirmou fazê-lo com base na indicação de bases eleitorais (movimentos sociais) e 36\%, a partir de suas relações pessoais. Apenas 17\% afirmou que a contratação se deu a partir da indicação do partido (é notável que só $2,1 \%$ tenha afirmado levar em conta a $e x-$ pertise dos contratados); $61,7 \%$ dos parlamentares afirmou ter contratado pessoas indicadas por movimentos sociais. Some-se ainda que, na média, os parlamentares afirmam dedicar $52 \%$ de seu tempo de trabalho ao atendimento das bases - dentro e fora da Câmara. Isto parece corroborar a hipótese de Leal, segundo a qual os legisladores petistas dividem sua lealdade à orientação partidária, de um lado, e à maximização eleitoral, de outro.

O quinto capítulo do livro deixa algo a desejar. Em vez de um aprofundamento analítico nos dados da pesquisa, o autor optou por descrever enfadonha e muito sucintamente a resposta de cada um dos parlamentares que responderam ao questionário. No lugar de uma explicação, o leitor depara-se com uma extensa listagem de opiniões individuais, muitas delas repetitivas, e o capítulo assume um formato similar a um relatório de pesquisa descritivo. $O$ autor faz menção às metodologias de análise de discurso, mas não as utiliza. Apenas merecem menção, pelo pitoresco e pela condição de outlier do seu autor (depois expulso do partido), as afirmações do deputado Babá: "O Legislativo está em decadência. O deputado federal está ligado à luta dos trabalhadores, seja através de enfrentamento diário, seja através de projetos para beneficiar os trabalhadores e destruir com [sic] a burguesia" (p. 94). Se realmente crê no que diz, seria impossível a Babá permanecer num partido que chegou ao governo numa democracia capitalista.

Em resumo, o trabalho de Leal oferece ao leitor uma descrição bastante sucinta das opiniões declaradas dos parlamentares petistas no momento em que o partido deixaria sua condição de oposicionista congênito aos governos nacionais. Avança muito pouco, porém, no tratamento analítico desse material, seja mediante o uso das técnicas de análise de discurso, seja pelo confronto das opiniões declaradas com o comportamento legislativo propriamente dito. Com isso, embora seja possível detectar correspondência entre a discussão teórica elaborada nos primeiros capítulos da obra e os dados colhidos mais adiante, o trabalho carece de um maior aprofundamento. Termina-se a leitura com a convicção de que as tensões percebidas de forma impressionista no discurso petista correspondem ao que se pode aferir por meio de um levantamento mais sistemático desse mesmo discurso; todavia, fica-se sem saber se as opiniões emitidas abertamente encontravam eco na atuação parlamentar efetiva do Partido dos Trabalhadores na oposição algo que poderia ser feito, reitero, confrontando-se as opiniões emitidas com a prática parlamentar, mensurável pelas votações.

De qualquer modo, esse PT ao qual o estudo se refere foi sepultado pela chegada do partido ao governo do país. A atuação parlamentar durante o governo Lula, o rigor inicial com os rebeldes, as tensões em torno das reformas e da política econômica, tudo isso mostrou que além 
da lealdade às instâncias partidárias, aos movimentos sociais ou ao eleitorado, a bancada petista viu-se diante da contingência de ser leal ao governo. Isto mudaria bastante o enfoque a ser adotado numa nova investigação que o autor pudesse vir a realizar com os legisladores. Mas após o cataclismo que se abateu sobre o governo Lula e o PT, quaisquer respostas que fossem dadas a uma enquête já não obedeceriam mais a condições normais de funcionamento da instituição em estudo. Ademais, será preciso saber se ainda haverá objeto.

\section{CLÁUDIO GONÇALVES COUTO é professor do Departamento de Política e do Programa de Estudos Pós-Graduados em Ciências So- ciais da PUC/SP. E-mail: claudio.couto@- pucsp.br}

\section{Interpretando significados de ruas do passado}

Fraya FREHSE. O tempo das ruas na São Paulo de fins do Império. São Paulo, Edusp, 2005. 271 páginas.

Heitor Frúgoli Jr.

Em resposta a críticas de Perry Anderson a seu livro Tudo que é sólido desmancha no ar (1986), Marshall Berman defendia a necessidade de um mergulho radical na reconstituição da vida cotidiana daqueles inseridos no torvelinho da modernidade, frisando uma especial atenção aos sinais que vêm das ruas (1987). Os ensaios densos de Berman, com ênfase nas mudanças socioculturais visíveis nos espaços públicos de metrópoles em distintos processos de modernização - Paris, Petersburgo, Nova York - repercutiam então em vários campos de estudo, embora se possa dizer que sua leitura dos bulevares parisienses muito tenha retomado do texto clássico de Walter Benjamin sobre a Paris oitocentista (1985 [1955] $\left.]^{1}\right)$.

Interessante lembrar que no Brasil, o escritor João do Rio (1881-1921) já havia assumido a própria condição de flanêur, ${ }^{2}$ a partir da qual produziu crônicas jornalísticas sobre a vida das ruas do Rio Janeiro da Belle Époque, traçando a fisionomia de seus tipos urbanos marginalizados, pobres, negros e mestiços, praticantes de um sem-número de "pequenas profissões", bem como de atividades festivas e religiosas, cujos artigos reunidos resultaram em A alma encantadora das ruas (1997 [1908]). Curiosamente, seus escritos sobre São Paulo, que visitou por várias vezes, caracterizamse por cenários triunfantes que revelam muito mais de si (e de suas relações com o Partido Republicano Paulista) do que da própria cidade (Schapochnik, 2004, pp. 11-18).

Nesse campo de abordagens sobre os espaços urbanos e seus atores sociais como contextos peculiares para investigações sobre o moderno, a recente publicação do livro de Fraya Frehse, $O$ tempo das ruas na São Paulo de fins do Império (baseado em dissertação de mestrado defendida na USP) oferece uma contribuição antropológica original, por meio de uma etnografia de fôlego de 